Supporting Information for

Inversion of Circular Dichroism Signals in Chiral Polythiophene Films Induced by End-on-oriented

\title{
Surface-segregated Monolayers
}

Fanji Wang $^{1,2}$, Kyohei Nakano ${ }^{1}$, Hiroshi Segawa ${ }^{3,4}$, and Keisuke Tajima ${ }^{1 *}$

${ }^{1}$ RIKEN Center for Emergent Matter Science (CEMS), 2-1 Hirosawa, Wako, Saitama 351-0198, Japan; ${ }^{2}$ Department of Applied Chemistry, Graduate School of Engineering, The University of Tokyo, 7-3-1 Hongo, Bunkyo-ku, Tokyo 113-8656, Japan; ${ }^{3}$ Research Center for Advanced Science and Technology, The University of Tokyo, 4-6-1 Komaba, Meguro-ku, Tokyo 153-8904, Japan; and ${ }^{4}$ Graduate School of Arts and

Sciences, The University of Tokyo, 3-8-1 Komaba, Meguro-ku, Tokyo 1538902, Japan

*keisuke.tajima@riken.jp 

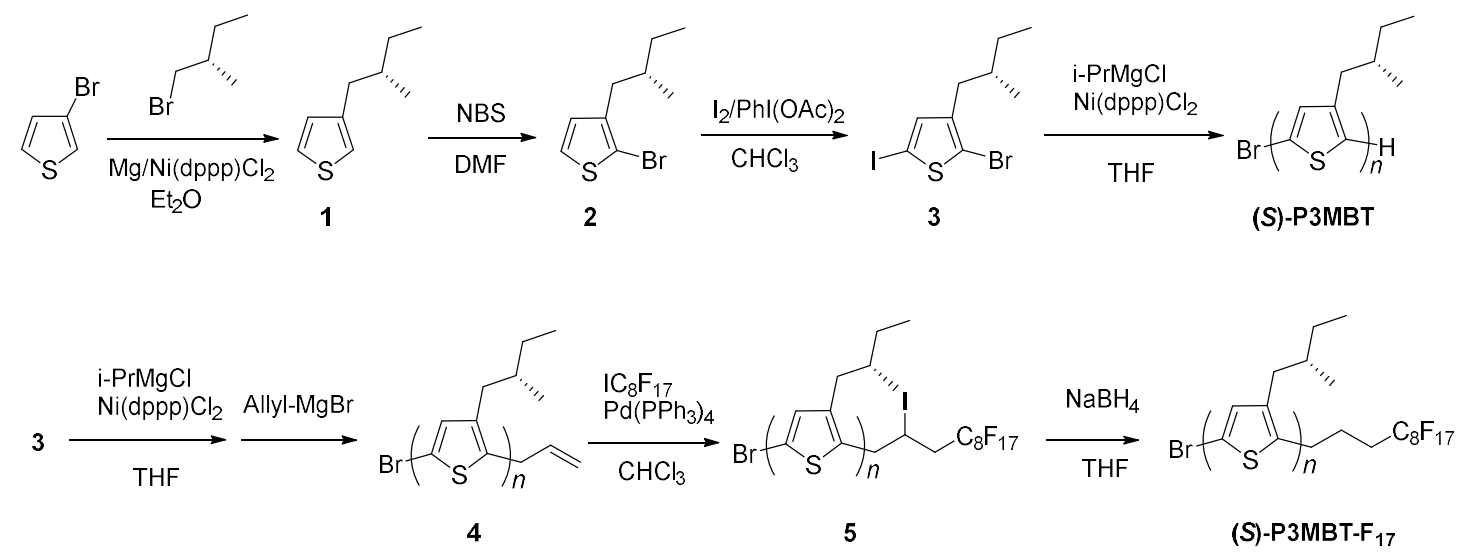

Scheme S1. Synthetic route for $(S)-\mathrm{P} 3 \mathrm{MBT}$ and $(S)-\mathrm{P} 3 \mathrm{MBT}-\mathrm{F}_{17}$.

\section{Synthetic procedures:}

\section{3-(S)-2-Methylbutylthiophene (1)}

(S)-1-Bromo-2-methylbutane (18.12 g, $120 \mathrm{mmol})$ was added dropwise to a suspension of magnesium ( $3.12 \mathrm{~g}, 130 \mathrm{mmol})$ and a small amount of $\mathrm{I}_{2}$ in diethyl ether $(120 \mathrm{ml})$ in an oven-dried $200 \mathrm{~mL}$ three-necked round bottom flask under $\mathrm{N}_{2}$. The mixture was reacted for $2 \mathrm{~h}$ to obtain the Grignard reagent. The solution was cooled to $0{ }^{\circ} \mathrm{C}$ and gradually transferred into a $500 \mathrm{~mL}$ flask charged with a diethyl ether solution $(200 \mathrm{~mL})$ of 3-bromothiophene $(16.3 \mathrm{~g}, 100 \mathrm{mmol})$ and 1,2-bis(diphenylphosphino)propane nickel(II) (Ni(dppp)Cl $; 5.42 \mathrm{~g}, 10 \mathrm{mmol}$ ) by a metal cannula. After the solution was refluxed at $40{ }^{\circ} \mathrm{C}$ overnight, the reaction was quenched with $\mathrm{HCl}$ aq. (1 M, $100 \mathrm{~mL})$. The organic layer was washed with water and brine successively and extracted with $\mathrm{CHCl}_{3}$, and then the organic extracts were dried over anhydrous $\mathrm{Na}_{2} \mathrm{SO}_{4}$. After filtration and concentration by vacuum evaporation, the crude compound was purified by vacuum distillation to obtain the product as a colorless oil $(9.16 \mathrm{~g}, 60 \%)$.

${ }^{1} \mathrm{H}$ NMR $\left(\mathrm{CDCl}_{3}, 300 \mathrm{MHz}\right): 0.87(\mathrm{~m}, 6 \mathrm{H}), 1.18$ and $1.39(\mathrm{ddd}, 2 \mathrm{H}), 1.63(\mathrm{~m}, 1 \mathrm{H}), 2.44$ and $2.62(\mathrm{dq}, 2 \mathrm{H}), 6.93(\mathrm{~m}, 2 \mathrm{H}), 7.23(\mathrm{~m}, 1 \mathrm{H})$. 


\section{2-Bromo-3-(S)-2-methylbutylthiophene (2)}

A solution of $1(8.83 \mathrm{~g}, 58 \mathrm{mmol})$ in DMF $(60 \mathrm{~mL})$ was placed in a $100 \mathrm{~mL}$ round bottom flask and cooled to $0{ }^{\circ} \mathrm{C}$ with protection from light. A solution $(20 \mathrm{~mL})$ of $N$ bromosuccinimide $(10.27 \mathrm{~g}, 57.7 \mathrm{mmol})$ in DMF was added dropwise to the solution. After warming to room temperature and stirring overnight, the solution was diluted with $\mathrm{CHCl}_{3}$, washed with saturated $\mathrm{NaHCO}_{3}$ aq., water, and brine successively, and then dried over anhydrous $\mathrm{Na}_{2} \mathrm{SO}_{4}$. After filtration and concentration by vacuum evaporation, the crude material was purified by vacuum distillation to obtain the product as a colorless oil $(6.7 \mathrm{~g}, 50 \%)$.

${ }^{1} \mathrm{H} \mathrm{NMR}\left(\mathrm{CDCl}_{3}, 300 \mathrm{MHz}\right): 0.88(\mathrm{~m}, 6 \mathrm{H}), 1.22$ and $1.40(\mathrm{ddd}, 2 \mathrm{H}), 1.67(\mathrm{~m}, 1 \mathrm{H}), 2.38$ and $2.56(\mathrm{dq}, 2 \mathrm{H}), 6.78(\mathrm{~d}, 1 \mathrm{H}), 7.19(\mathrm{~d}, 1 \mathrm{H})$.

\section{2-Bromo-3-(S)-2-methylbutyl-5-iodothiophene (3)}

A solution of $2(6.71 \mathrm{~g}, 28.8 \mathrm{mmol})$ in $\mathrm{CHCl}_{3}(100 \mathrm{~mL})$ was placed in a round bottom flask and cooled to $0{ }^{\circ} \mathrm{C}$ with protection from light. $\mathrm{I}_{2}(4.39 \mathrm{~g}, 17.3 \mathrm{mmol}, 0.6$ eq.) and iodobenzene diacetate $(5.56 \mathrm{~g}, 17.3 \mathrm{mmol}, 0.6 \mathrm{eq}$.) were added to the solution. The mixture was warmed to room temperature and stirred overnight before quenching with saturated $\mathrm{Na}_{2} \mathrm{~S}_{2} \mathrm{O}_{3}$ aq. (100 mL). The organic layer was washed with water and brine successively and extracted with $\mathrm{CHCl}_{3}$, and the organic extracts were dried over anhydrous $\mathrm{Na}_{2} \mathrm{SO}_{4}$. After filtration and concentration by vacuum evaporation, the crude material was purified by column chromatography and vacuum distillation to obtain the product as a yellow oil $(8.5 \mathrm{~g}, 83 \%)$. 
${ }^{1} \mathrm{H}-\mathrm{NMR}\left(\mathrm{CDCl}_{3}, 300 \mathrm{MHz}\right): 0.87(\mathrm{~m}, 6 \mathrm{H}), 1.21$ and $1.38(\mathrm{ddd}, 2 \mathrm{H}), 1.65(\mathrm{~m}, 1 \mathrm{H}), 2.34$ and $2.52(\mathrm{dq}, 2 \mathrm{H}), 6.94(\mathrm{~s}, 1 \mathrm{H})$. HRMS (FD) $m / z$ calcd. for $\mathrm{C}_{9} \mathrm{H}_{12} \mathrm{Br}_{1} \mathrm{I}_{1} \mathrm{~S}_{1}$ : 357.88878, found: 357.89215 .

\section{(S)-P3MBT}

A solution of $3(1.0 \mathrm{~g}, 2.79 \mathrm{mmol})$ in anhydrous THF $(15 \mathrm{~mL})$ was placed in an ovendried $100 \mathrm{~mL}$ two-necked round bottom flask, flushed with $\mathrm{N}_{2}$ for $30 \mathrm{~min}$, and cooled to $0{ }^{\circ} \mathrm{C}$. Isopropyl magnesium bromide $(1.33 \mathrm{~mL}, 2.66 \mathrm{mmol}, 0.95$ eq. $)$ was added dropwise to the flask under $\mathrm{N}_{2}$ and the reaction mixture was stirred at $0{ }^{\circ} \mathrm{C}$ for $1 \mathrm{~h}$. The solution was diluted to $50 \mathrm{~mL}$ by adding anhydrous THF and $\mathrm{Ni}(\mathrm{dppp}) \mathrm{Cl}_{2}(60.4 \mathrm{mg}$, $0.11 \mathrm{mmol}$ ) was added immediately. The reaction mixture was stirred for $1 \mathrm{~h}$ at $35^{\circ} \mathrm{C}$ and quenched with $\mathrm{HCl}$ aq. (6 M, $50 \mathrm{~mL}$ ). The mixture was poured into $\mathrm{MeOH}$, filtered, and then washed with $\mathrm{MeOH}$ and hexane by Soxhlet extraction and eluted with $\mathrm{CHCl}_{3}$. After concentration by vacuum evaporation, the product was collected as a dark purple solid (295 mg, 70\%).

${ }^{1} \mathrm{H} \mathrm{NMR}\left(\mathrm{CDCl}_{3}, 300 \mathrm{MHz}\right): 0.94(\mathrm{~m}, 6 \mathrm{H}), 1.25$ and 1.49 (ddd, 2H), $1.78(\mathrm{~m}, 1 \mathrm{H}), 2.62$ and $2.79(\mathrm{dq}, 2 \mathrm{H}), 6.95(\mathrm{~s}, 1 \mathrm{H})$.

\section{(S)-P3MBT-allyl (4)}

(S)-P3MBT-allyl was synthesized by the same procedure as $(S)$-P3MBT, but the reaction was quenched by adding excess allyl magnesium bromide (10 eq. with respect to the chain ends) to functionalize the polymer end-group (283 $\mathrm{mg}, 70 \%)$.

${ }^{1} \mathrm{H}$ NMR $\left(\mathrm{CDCl}_{3}, 300 \mathrm{MHz}\right): 0.94(\mathrm{~m}, 6 \mathrm{H}), 1.25$ and 1.49 (ddd, 2H), 1.78 (m, 1H), 2.62 and $2.79(\mathrm{dq}, 2 \mathrm{H}), 3.49(\mathrm{~d}, 0.08 \mathrm{H}), 5.12(\mathrm{t}, 0.08 \mathrm{H}), 5.97(\mathrm{~m}, 0.04 \mathrm{H})$, and $6.95(\mathrm{~s}, 1 \mathrm{H})$. 


\section{(S)-P3MBT-F $17-I$ (5)}

A solution of 4 (283 mg, $0.094 \mathrm{mmol})$ and 1-iodoperfluorooctane (12 g, $22 \mathrm{mmol})$ in $\mathrm{CHCl}_{3}(60 \mathrm{~mL})$ were placed in a $100 \mathrm{~mL}$ oven-dried flask and flushed with $\mathrm{N}_{2}$ for 30 min. Tetrakis(triphenylphosphine)palladium(0) $(250 \mathrm{mg}, 0.16 \mathrm{mmol})$ was added to the solution under $\mathrm{N}_{2}$ and the reaction mixture was stirred for $48 \mathrm{~h}$ under reflux at $80{ }^{\circ} \mathrm{C}$. The solution was washed with water and brine, and then dried over anhydrous $\mathrm{Na}_{2} \mathrm{SO}_{4}$. After filtration and concentration by vacuum evaporation, the remaining dark purple solid was washed with $\mathrm{MeOH}$ and hexane by Soxhlet extraction and eluted with $\mathrm{CHCl}_{3}$. The polymer solution in $\mathrm{CHCl}_{3}$ was passed through a column filled with $\mathrm{Al}_{2} \mathrm{O}_{3}$ and celite, and then kept as a concentrated solution for the next step.

${ }^{1} \mathrm{H} \mathrm{NMR}\left(\mathrm{CDCl}_{3}, 300 \mathrm{MHz}\right): 0.94(\mathrm{~m}, 6 \mathrm{H}), 1.25$ and 1.49 (ddd, 2H), 1.78 (m, 1H), 2.62 and $2.79(\mathrm{dq}, 2 \mathrm{H}), 3.41(\mathrm{~d}, 0.08 \mathrm{H}), 4.42(\mathrm{~m}, 0.04 \mathrm{H})$, and $6.95(\mathrm{~s}, 1 \mathrm{H})$.

\section{(S)-P3MBT-F 17}

The concentrated solution of $\mathbf{5}$ was diluted with THF $(15 \mathrm{~mL})$ and was added to a stirred slurry of $\mathrm{NaBH}_{4}(6.0 \mathrm{~g})$ in anhydrous THF $(45 \mathrm{~mL})$, and then refluxed at $80{ }^{\circ} \mathrm{C}$ for $18 \mathrm{~h}$. The solution was washed with water and brine and dried over anhydrous $\mathrm{Na}_{2} \mathrm{SO}_{4}$. After filtration, the solution was concentrated by vacuum evaporation, and the remaining solid was washed with $\mathrm{MeOH}$ and hexane by Soxhlet extraction and eluted with $\mathrm{CHCl}_{3}$. The concentrated sediment of dark red powder was collected by filtration and dried under vacuum (140 mg, 42\%).

${ }^{1} \mathrm{H} \mathrm{NMR}\left(\mathrm{CDCl}_{3}, 300 \mathrm{MHz}\right): 0.94$ (m, 6H), 1.25 and 1.49 (ddd, 2H), 1.78 (m, 1H), 2.62 and $2.79(\mathrm{dq}, 2 \mathrm{H}), 6.95(\mathrm{~s}, 1 \mathrm{H})$. 


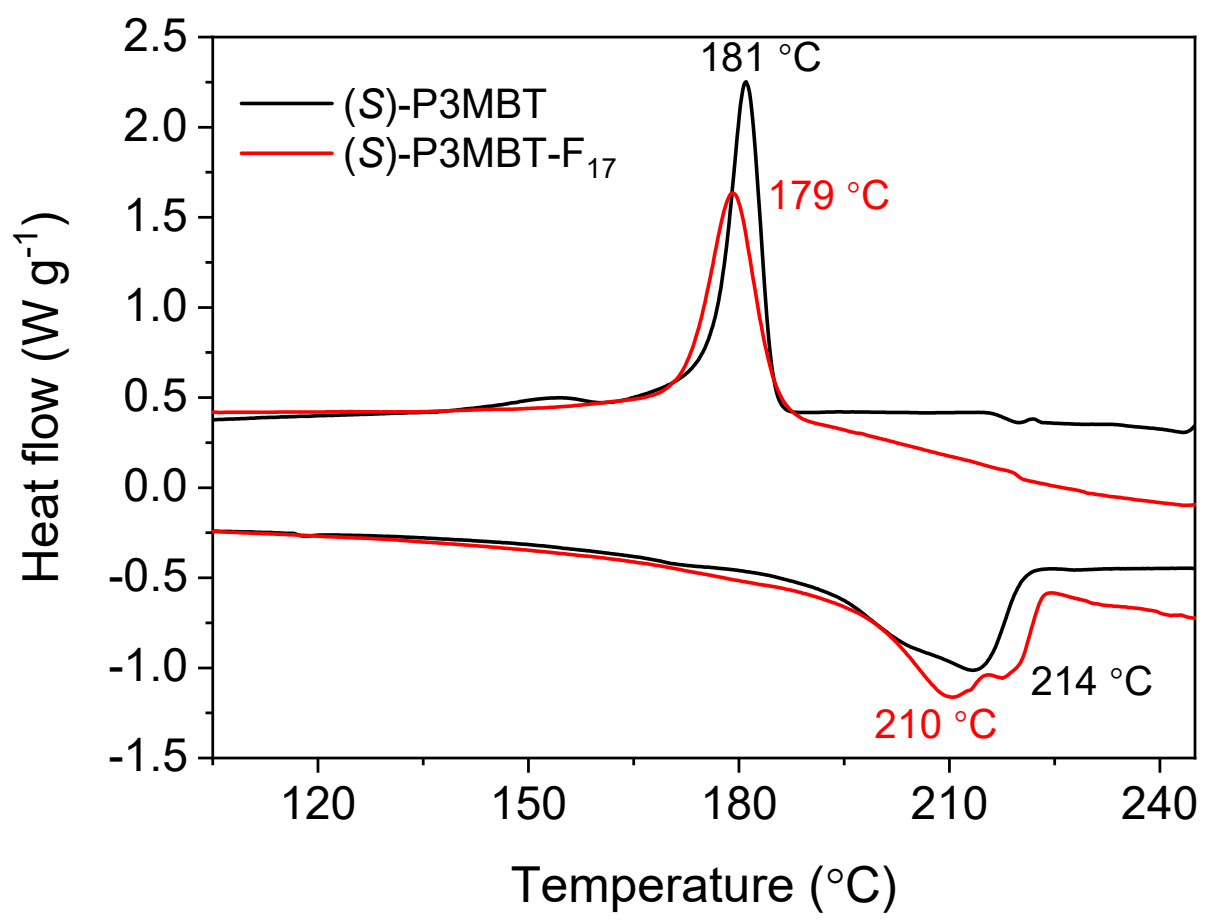

Figure S1. Differential scanning calorimetry of $(S)-\mathrm{P} 3 \mathrm{MBT}$ and $(S)-\mathrm{P} 3 \mathrm{MBT}-\mathrm{F}_{17}$ with heating and cooling traces at a rate of $10{ }^{\circ} \mathrm{C} \mathrm{min}^{-1}$. 
(a)

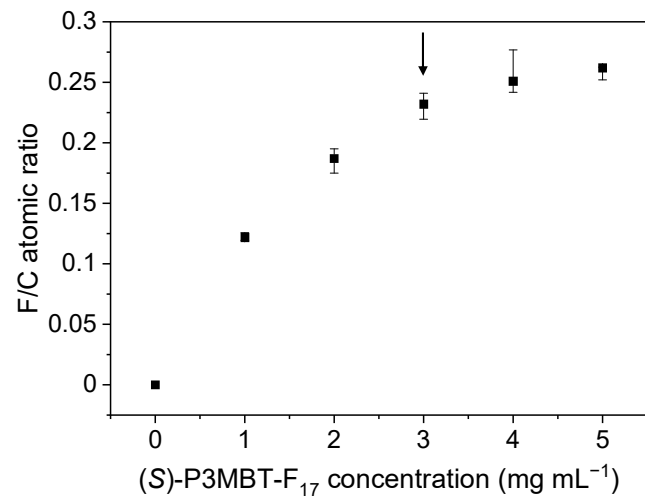

(b)

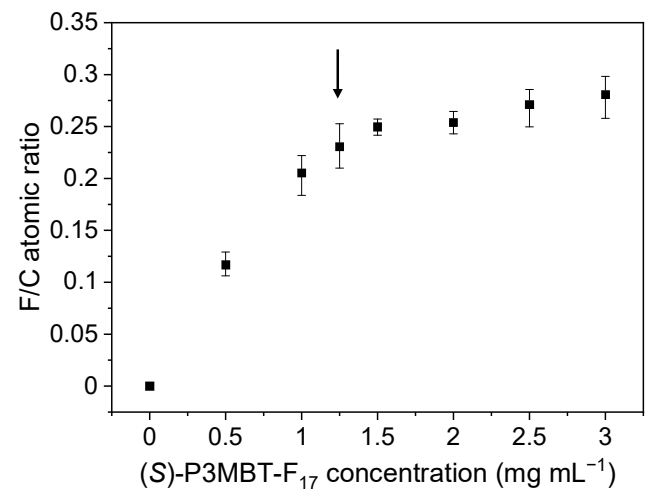

Figure S2. Surface $\mathrm{F} / \mathrm{C}$ atomic ratio as a function of $(S)-\mathrm{P} 3 \mathrm{MBT}-\mathrm{F}_{17}$ concentration in

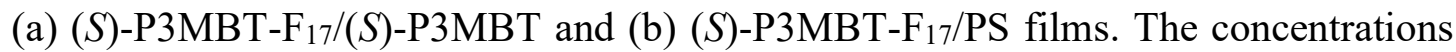
indicated by the arrows were used to prepare the SSMs.

\section{Surface segregation behavior of $(S)$-P3MBT-F 17 in $(S)$-P3MBT and PS films}

The surface segregation behavior of $(S)-\mathrm{P} 3 \mathrm{MBT}-\mathrm{F}_{17}$ in $(S)-\mathrm{P} 3 \mathrm{MBT}$ and PS films was studied by XPS (Figure S2). (S)-P3MBT-F $17\left(0-5 \mathrm{mg} \mathrm{mL}^{-1}\right) /(S)-\mathrm{P} 3 \mathrm{MBT}\left(2 \mathrm{mg} \mathrm{mL}^{-1}\right)$ and $(S)-\mathrm{P}_{3} \mathrm{MBT}_{-} \mathrm{F}_{17}\left(0-3 \mathrm{mg} \mathrm{mL} \mathrm{L}^{-1}\right) / \mathrm{PS}\left(3.5 \mathrm{mg} \mathrm{mL}^{-1}\right)$ were prepared by spin-coating from the mixed solutions. The $\mathrm{F} / \mathrm{C}$ atomic ratio increased as the $(S)-\mathrm{P} 3 \mathrm{MBT}-\mathrm{F}_{17}$ concentration increased and became saturated when the surface was fully covered by the SSM. The F/C ratio at the saturation point was about 0.25 for the two films, which is close to the calculated value $(0.252)$ based on a bilayer model (Ton-That et al. Langmuir 2000, 16, 2281). These results indicate a high coverage of (S)-P3MBT-F 17 on the surface of $(S)$-P3MBT and PS films. $(S)-\mathrm{P} 3 \mathrm{MBT}-\mathrm{F}_{17}\left(3 \mathrm{mg} \mathrm{mL}^{-1}\right) /(S)-\mathrm{P} 3 \mathrm{MBT}$ $\left(2 \mathrm{mg} \mathrm{mL}^{-1}\right)$ and $(S)-\mathrm{P} 3 \mathrm{MBT}-\mathrm{F}_{17}\left(1.25 \mathrm{mg} \mathrm{mL}^{-1}\right) / \mathrm{PS}\left(3.5 \mathrm{mg} \mathrm{mL}^{-1}\right)$ films were used for the subsequent measurements. 

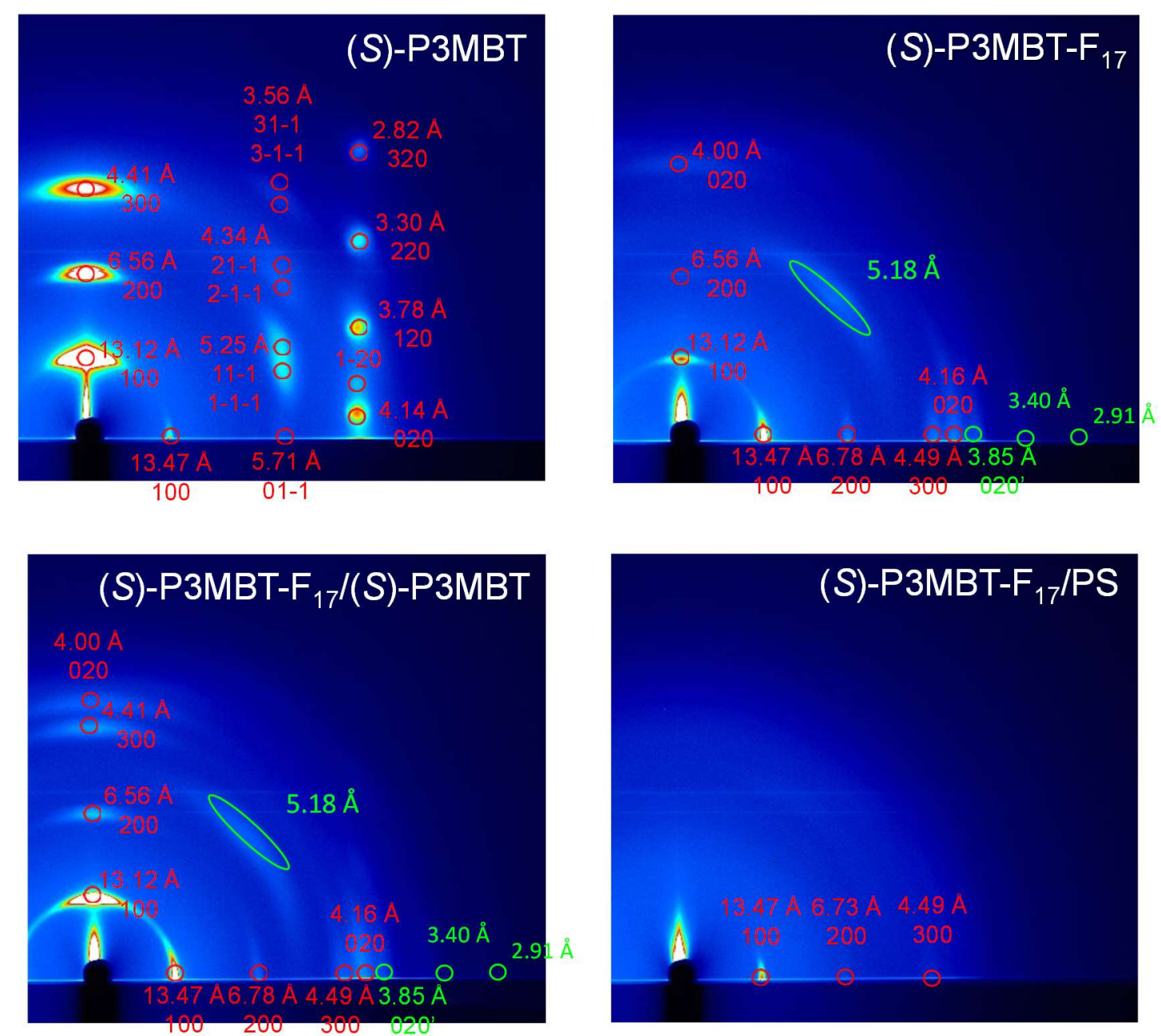

Figure S3. 2D GIWAXS patterns of $(S)$-P3MBT, $(S)$-P3MBT-F $17,(S)-\mathrm{P}_{3} \mathrm{MBT}_{17} \mathrm{~F}_{17} /(S)$ P3MBT, and $(S)-\mathrm{P} 3 \mathrm{MBT}-\mathrm{F}_{17} / \mathrm{PS}$ films. Several diffraction signals (indicated in green) are unassigned for the $(S)-\mathrm{P}_{3} \mathrm{MBT}_{-\mathrm{F}_{17}}$ and $(S)-\mathrm{P} 3 \mathrm{MBT}_{17} /(S)-\mathrm{P} 3 \mathrm{MBT}$ films. 

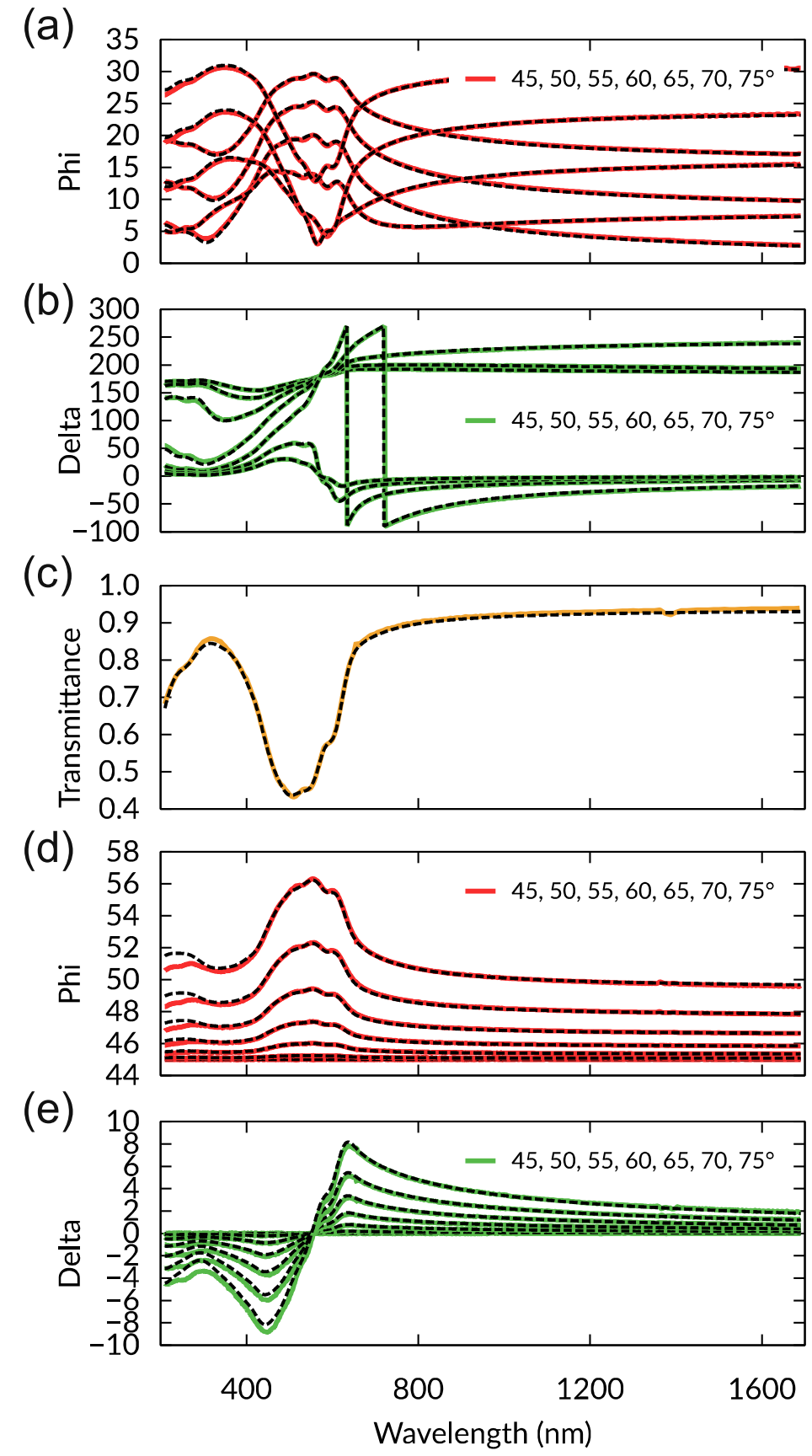

Figure S4. Spectroscopic ellipsometry results of the $(S)$-P3MBT pristine film prepared on a fused silica substrate. (a) Phi and (b) delta in reflection geometry with incident angles from $45^{\circ}$ to $75^{\circ}$. (c) Transmittance with $90^{\circ}$ incident light angle. (d) Phi and (e) delta in transmission geometry with incident angles from $45^{\circ}$ to $75^{\circ}$. The black dashed lines are fitting results using a fused silica/organic layer structure. The optical anisotropy of the organic layer is included in this fitting. 

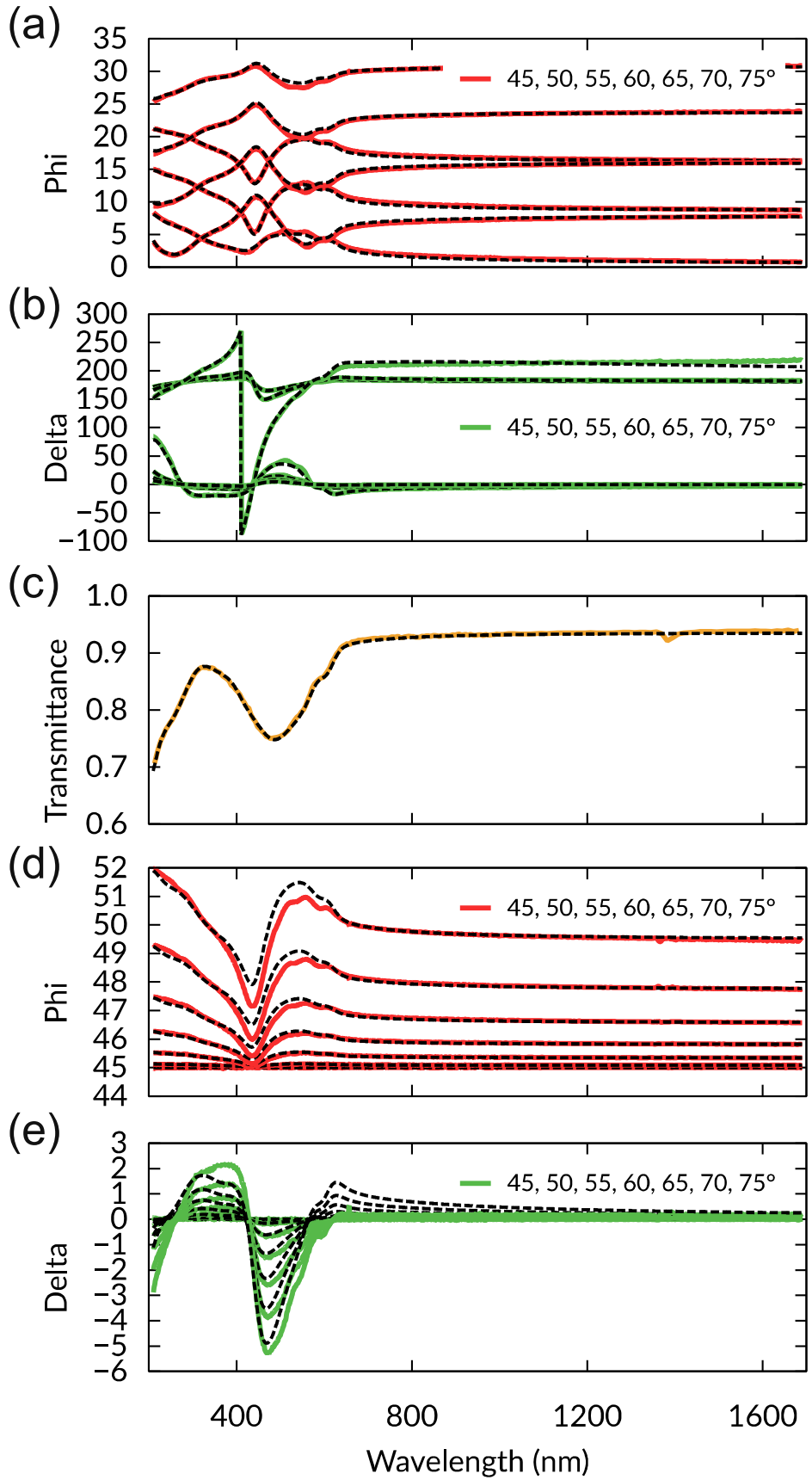

Figure S5. Spectroscopic ellipsometry measurement results of the (S)-P3MBT-F 17 pristine film prepared on a fused silica substrate. (a) Phi and (b) delta in reflection geometry with incident angles from $45^{\circ}$ to $75^{\circ}$. (c) Transmittance with $90^{\circ}$ incident light angle. (d) Phi and (e) delta in transmission geometry with incident angles from $45^{\circ}$ to $75^{\circ}$. The black dashed lines are fitting results using a fused silica/organic layer structure. The optical anisotropy of the organic layer is included in this fitting. 

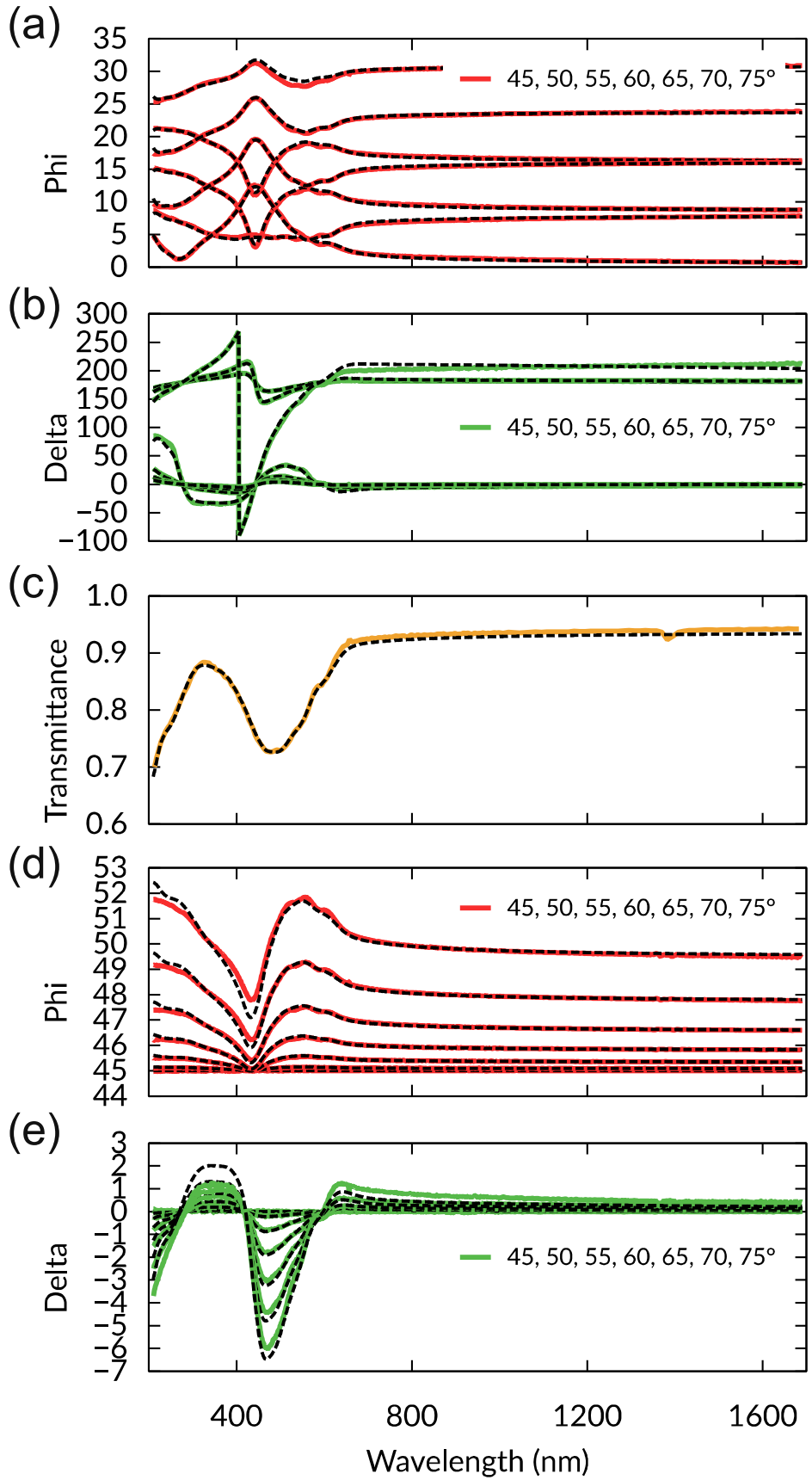

Figure S6. Spectroscopic ellipsometry measurement results of the (S)-P3MBT-F $17 /(S)$ P3MBT mixed film prepared on a fused silica substrate. (a) Phi and (b) delta in reflection geometry with incident angles from $45^{\circ}$ to $75^{\circ}$. (c) Transmittance with $90^{\circ}$ incident light angle. (d) Phi and (e) delta in transmission geometry with incident angles from $45^{\circ}$ to $75^{\circ}$. The black dashed lines are fitting results using a fused silica/organic layer structure. The optical anisotropy of the organic layer is included in this fitting. 


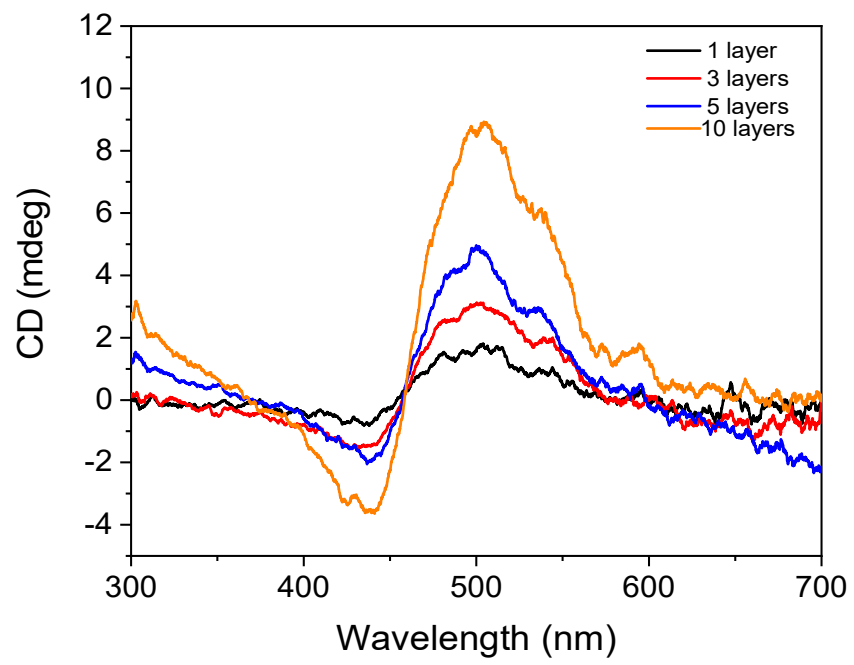

Figure S7 CD spectra of the stacked (S)-P3MBT-F 17 films (1, 3, 5, and 10 layers). 
(a)

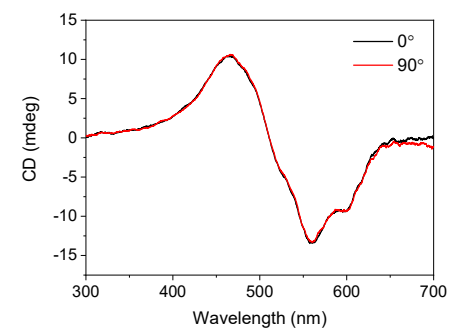

(b)

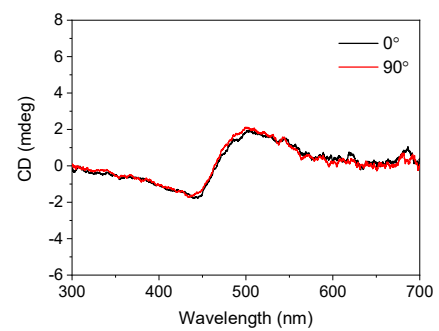

(c)

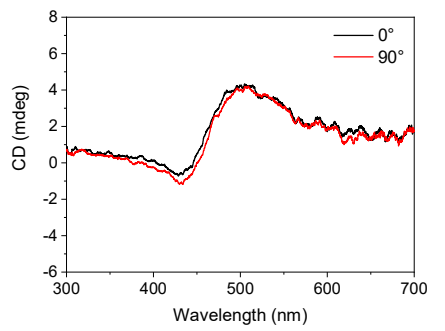

Figure S8. CD spectra of (a) (S)-P3MBT, (b) (S)-P3MBT-F 17 , and (c) (S)-P3MBT$\mathrm{F}_{17} /(S)$-P3MBT films with sample angles of $0^{\circ}$ (black) and $90^{\circ}$ (red). The CD signals do not depend on the sample angles relative to the light axis, indicating that the effects of the in-plane optical anisotropy on the CD signal are negligible. 
(a)

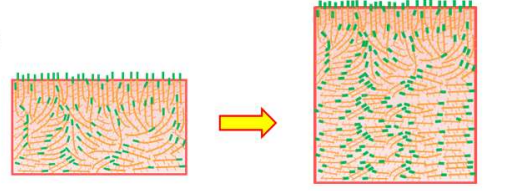

Thin (S)-P3MBT-F 17

Thick (S)-P3MBT-F 17 (b)

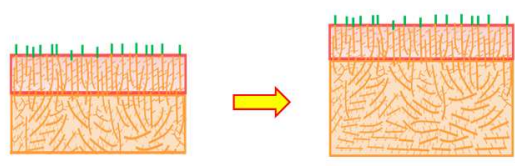

Thin (S)-P3MBT-F $17 /(S)-P 3 M B T$ Thick $(S)-P 3 M B T-F_{17} /(S)-P 3 M B T$
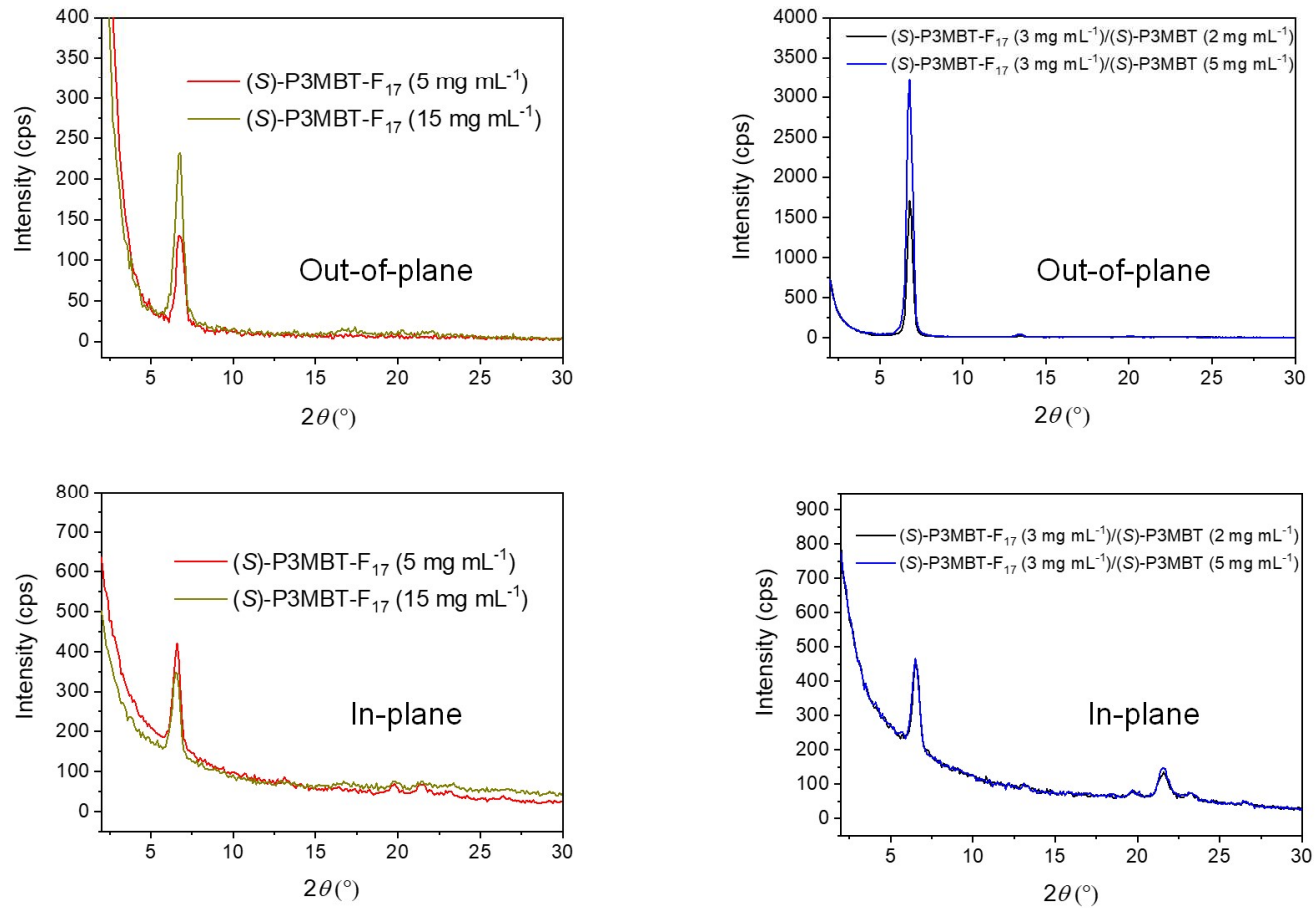

Figure S9. Schematics and out-of-plane and in-plane XRD diffraction patterns of (a) $(S)-\mathrm{P}_{3} \mathrm{MBT}_{-\mathrm{F}_{17}}\left(5\right.$ and $\left.15 \mathrm{mg} \mathrm{mL}^{-1}\right)$ and (b) $(S)-\mathrm{P} 3 \mathrm{MBT}^{-F_{17}}\left(3 \mathrm{mg} \mathrm{mL}^{-1}\right) /(\mathrm{S})-\mathrm{P} 3 \mathrm{MBT}$ ( 2 and $5 \mathrm{mg} \mathrm{mL}^{-1}$ ) films. In the schematics, the semifluoroalkyl group is shown in green and the polythiophene with the chiral side chains is shown in orange. 

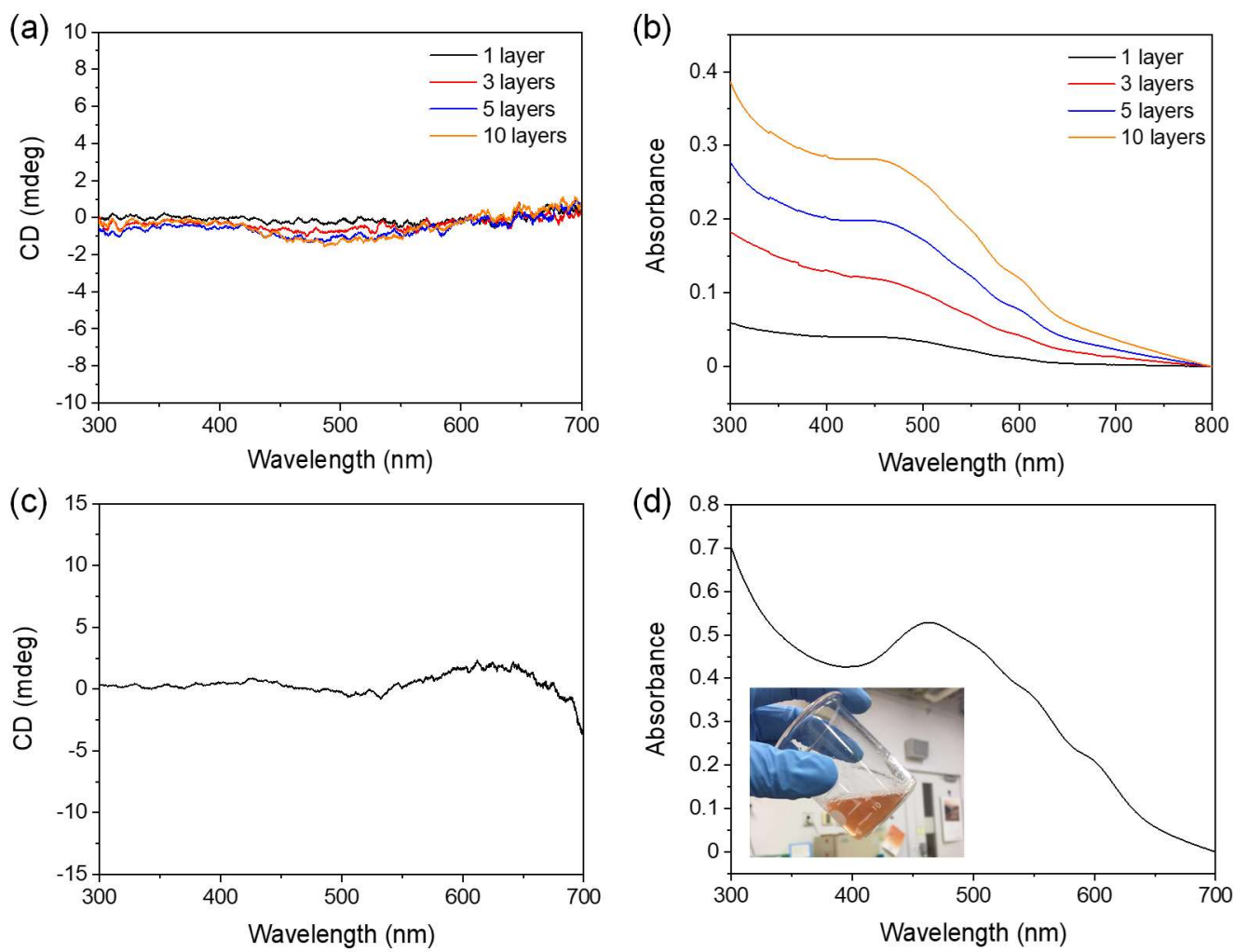

Figure S10. (a) CD and (b) UV-vis absorption spectra of the multilayered (S)-P3MBT$\mathrm{F}_{17} / \mathrm{PS}$ films. (c) CD and (d) UV-vis absorption spectra of the (S)-P3MBT-F $17 / \mathrm{PS}$ films dispersed in water. Inset in (d): photograph of the dispersion in water. 


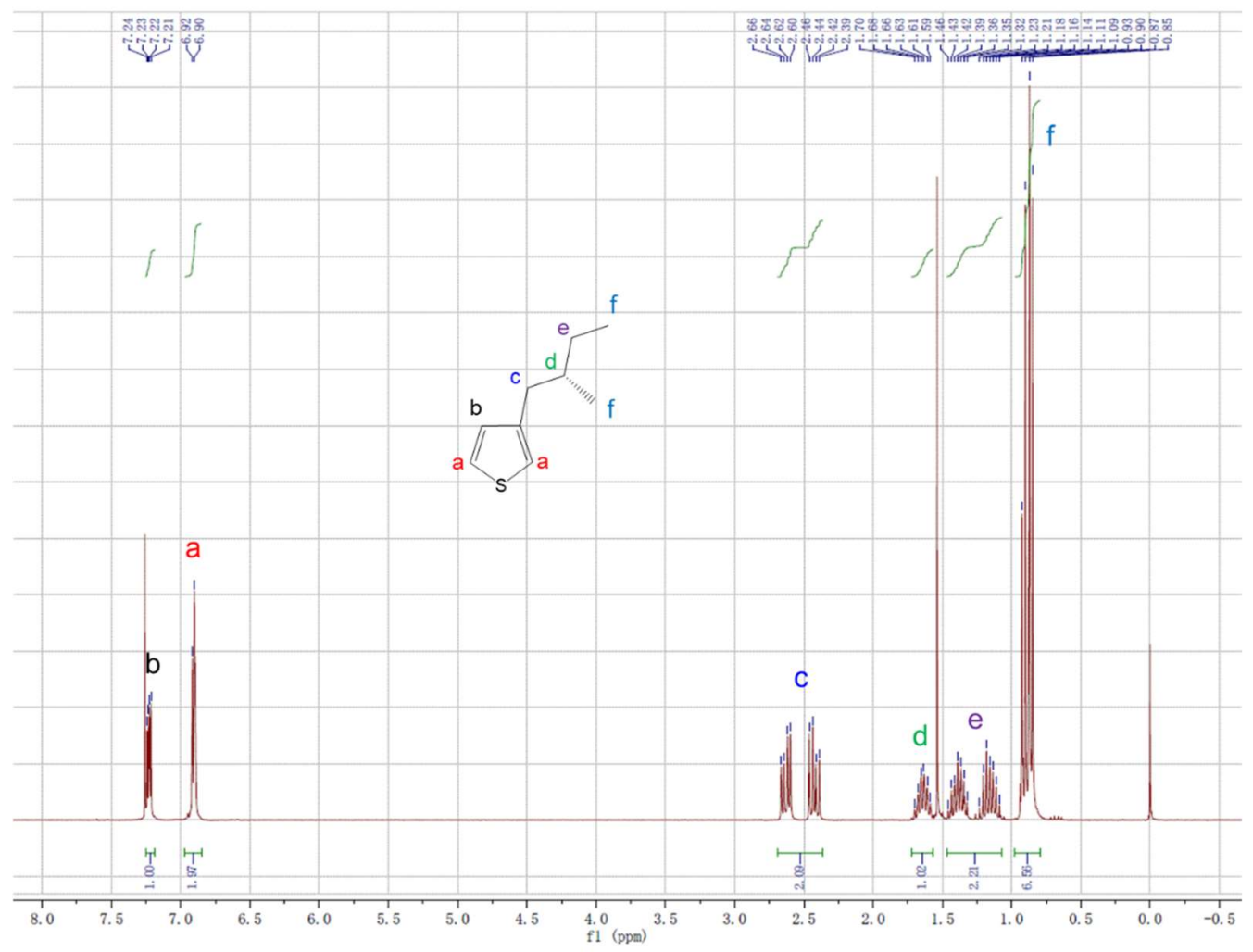

Figure S11. ${ }^{1} \mathrm{H}$ NMR spectrum of 3-(S)-2-methylbutylthiophene.

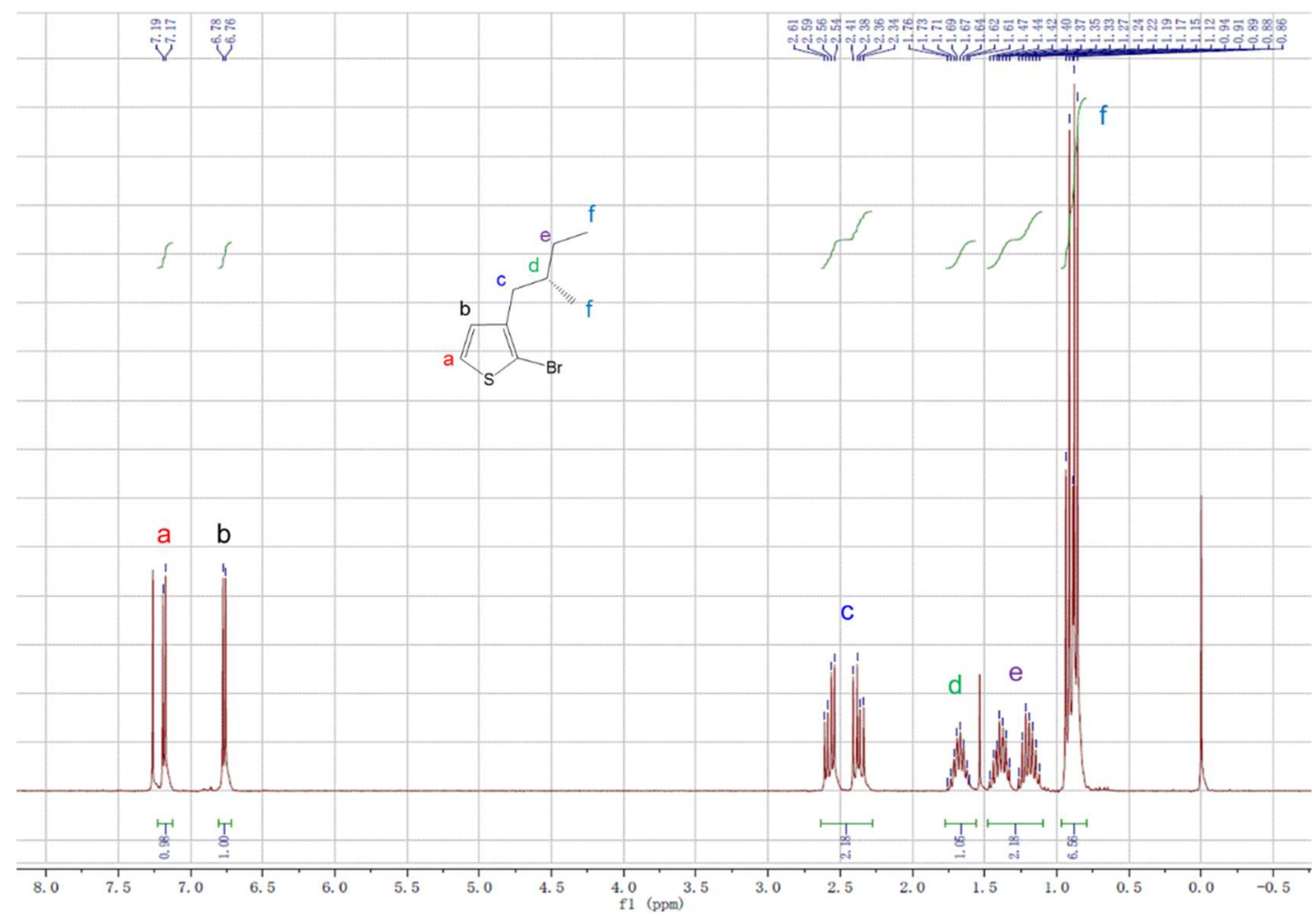

Figure S12. ${ }^{1} \mathrm{H}$ NMR spectrum of 2-bromo-3-(S)-2-methylbutylthiophene. 


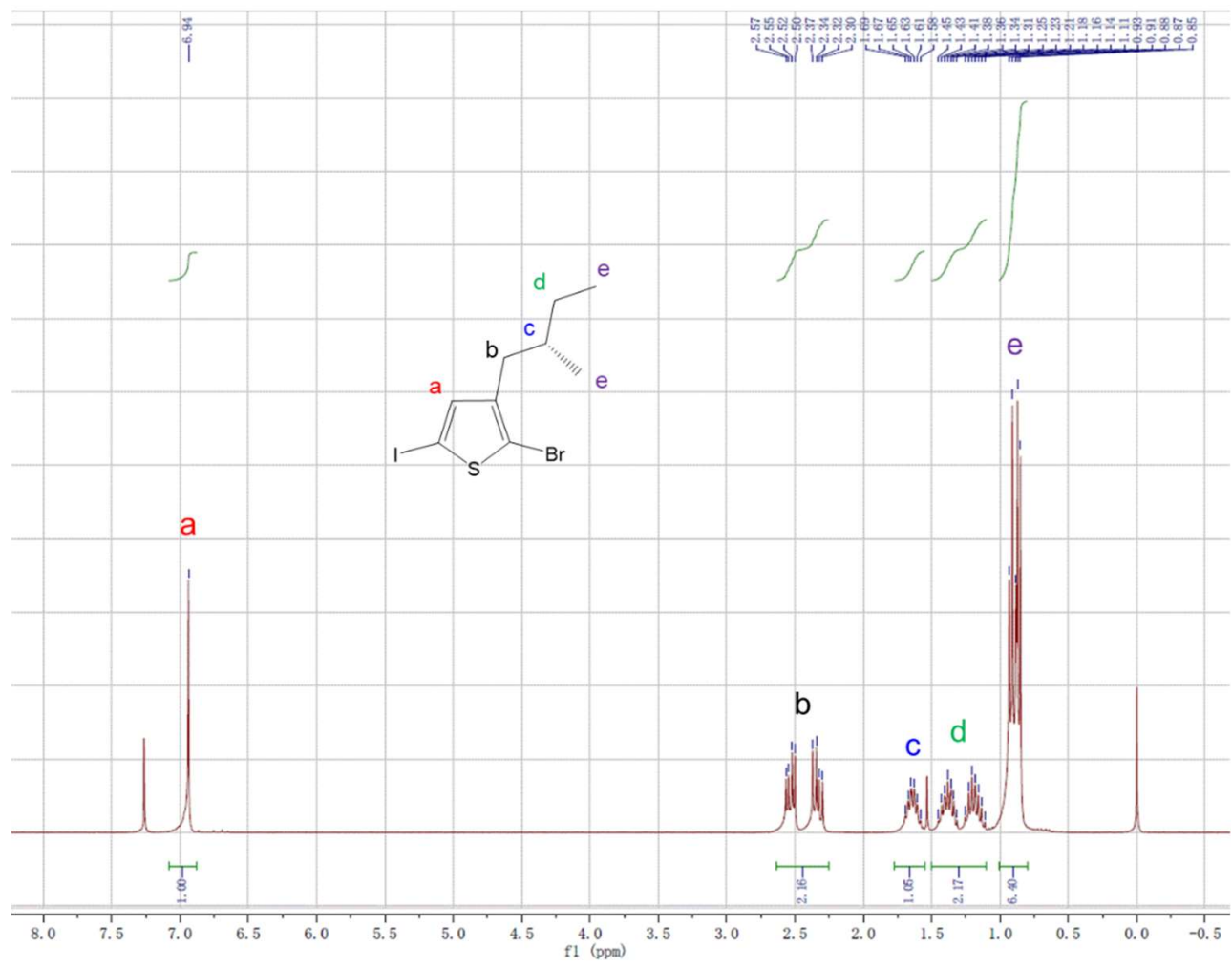

Figure S13. ${ }^{1} \mathrm{H}$ NMR spectrum of 2-bromo-3-(S)-2-methylbutyl-5-iodothiophene.

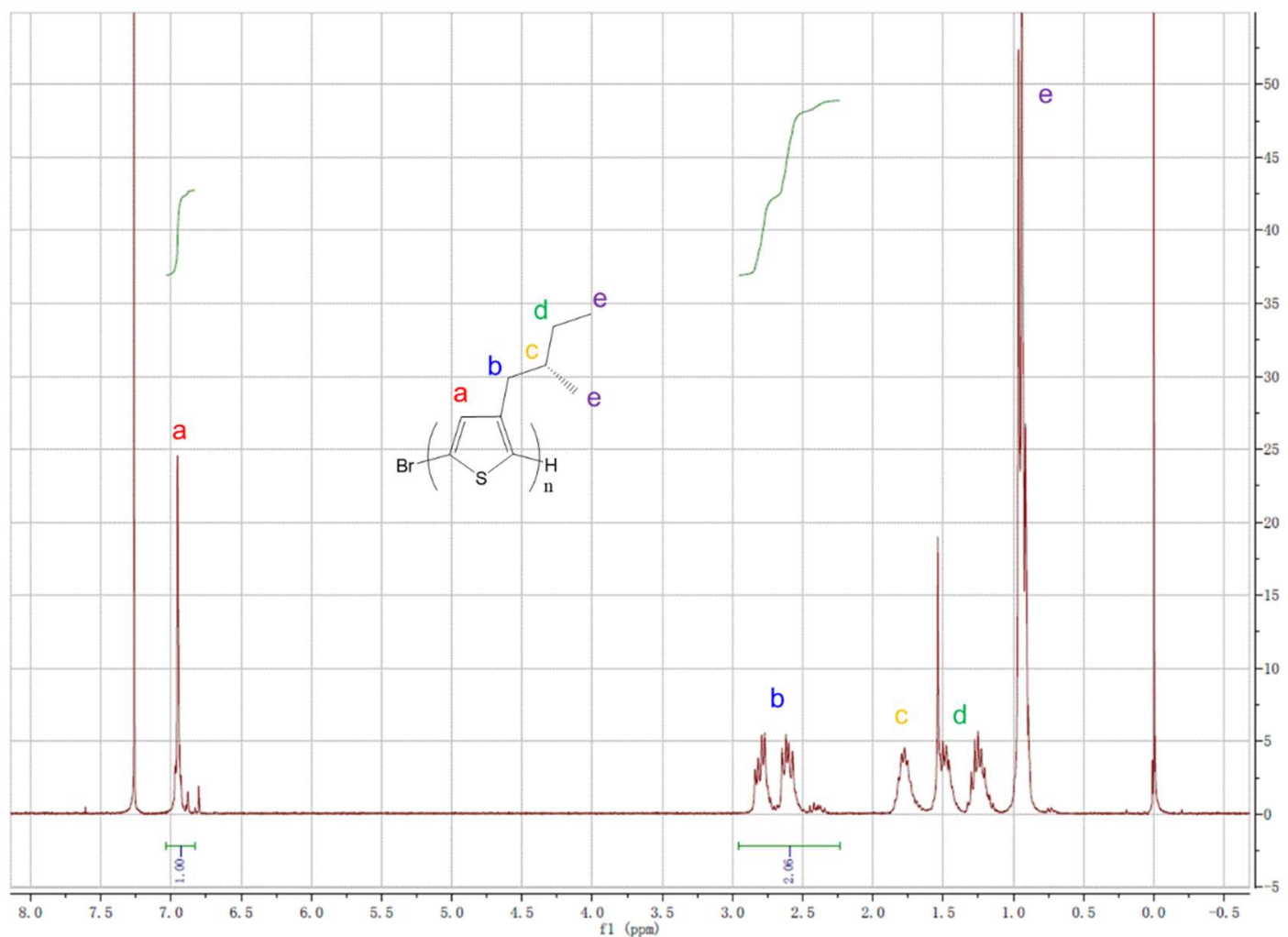

Figure S14. ${ }^{1} \mathrm{H}$ NMR spectrum of $(S)-\mathrm{P} 3 \mathrm{MBT}$. 


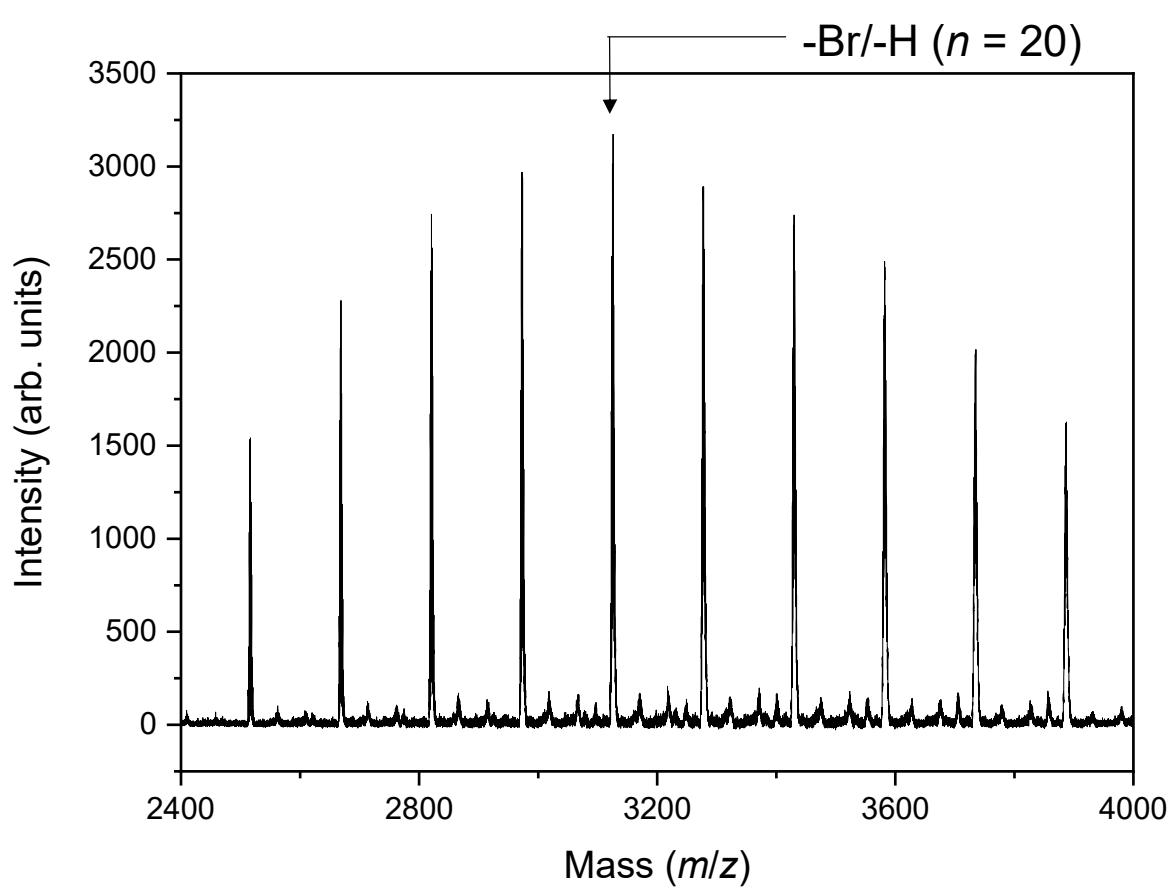

Figure S15. MALDI-TOF-MS spectrum of (S)-P3MBT.

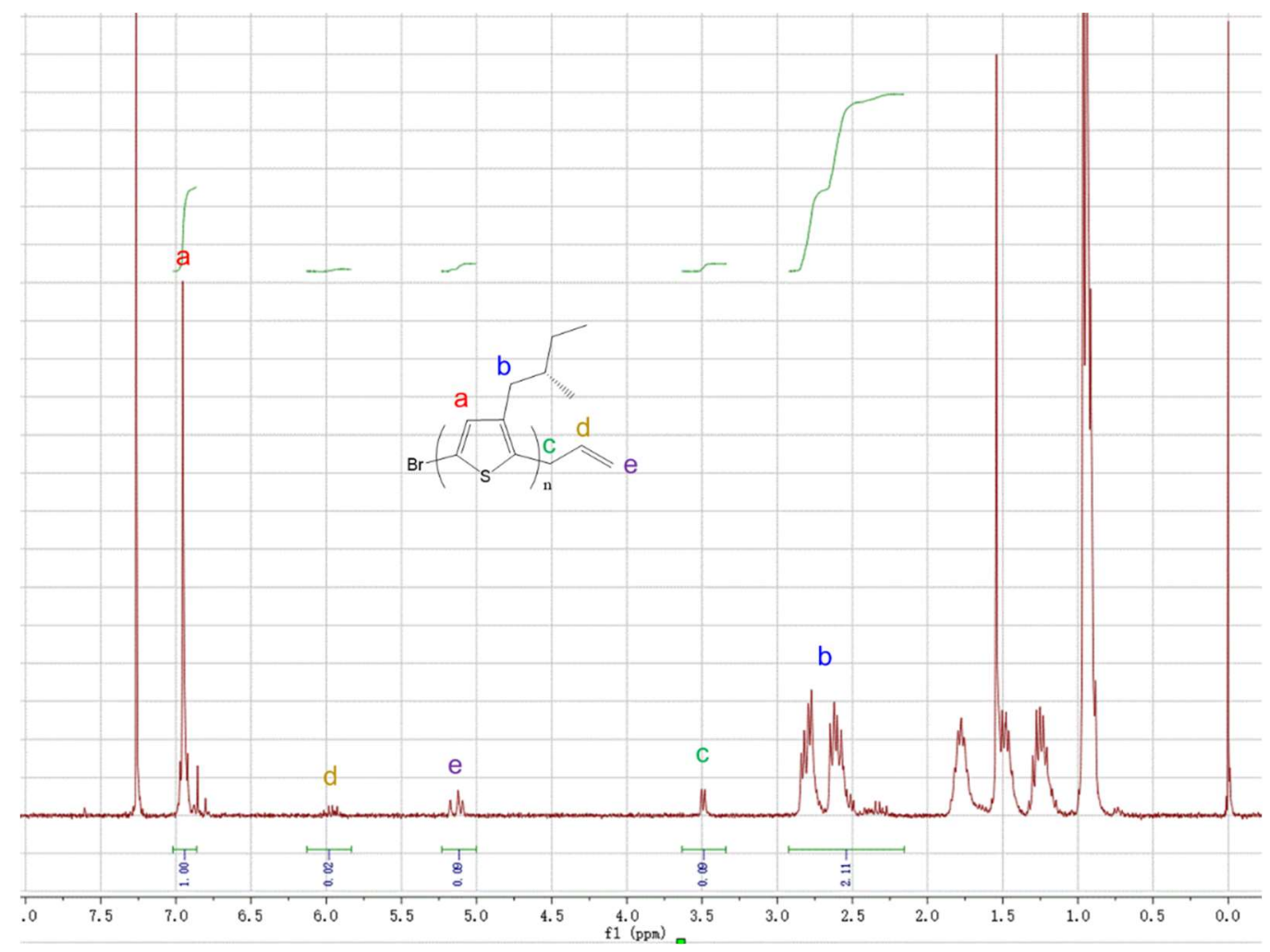

Figure S16. ${ }^{1} \mathrm{H}$ NMR spectrum of $(S)$-P3MBT-allyl. 


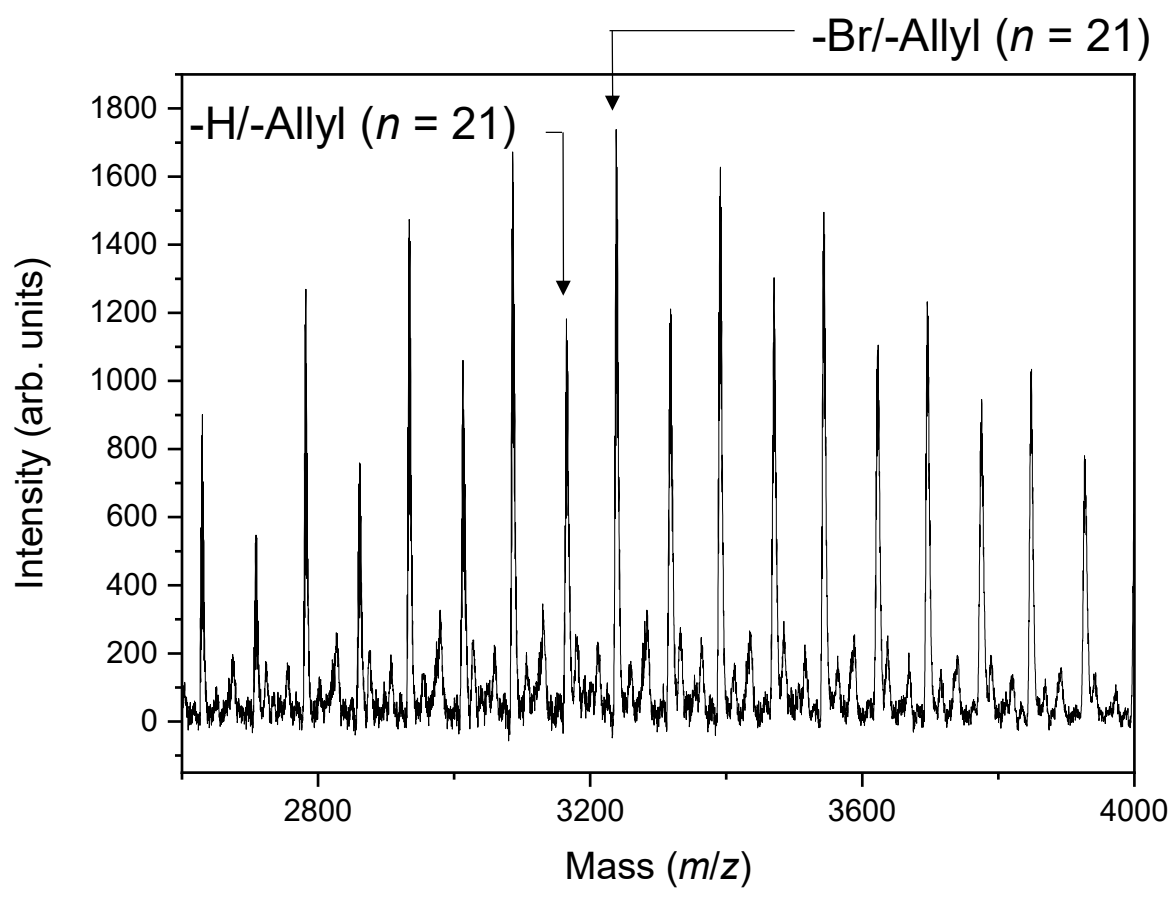

Figure S17. MALDI-TOF-MS spectrum of (S)-P3MBT-allyl.

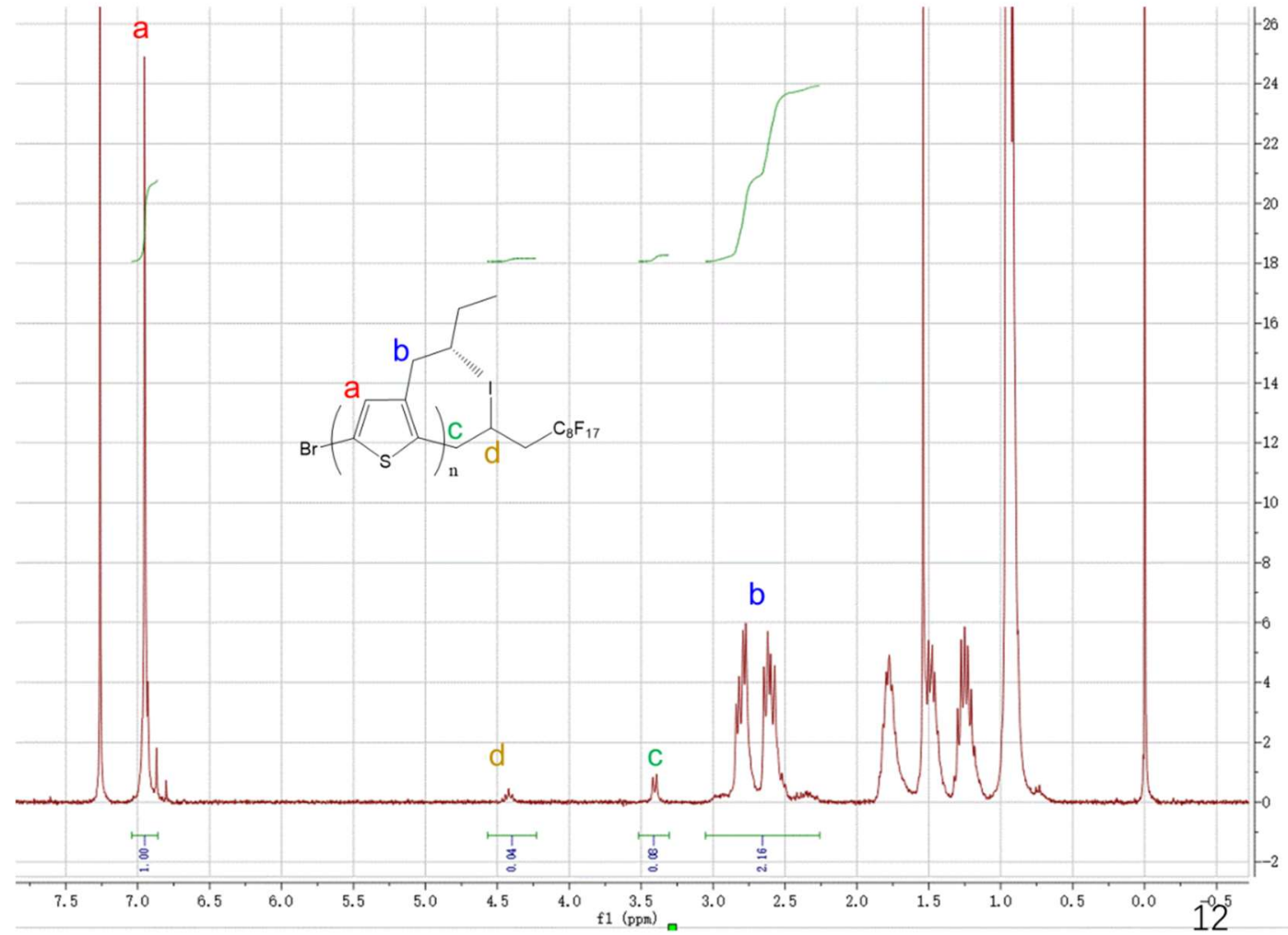

Figure S18. ${ }^{1} \mathrm{H}$ NMR spectrum of $(S)-\mathrm{P} 3 \mathrm{MBT}-\mathrm{F}_{17-\mathrm{I}}$. 


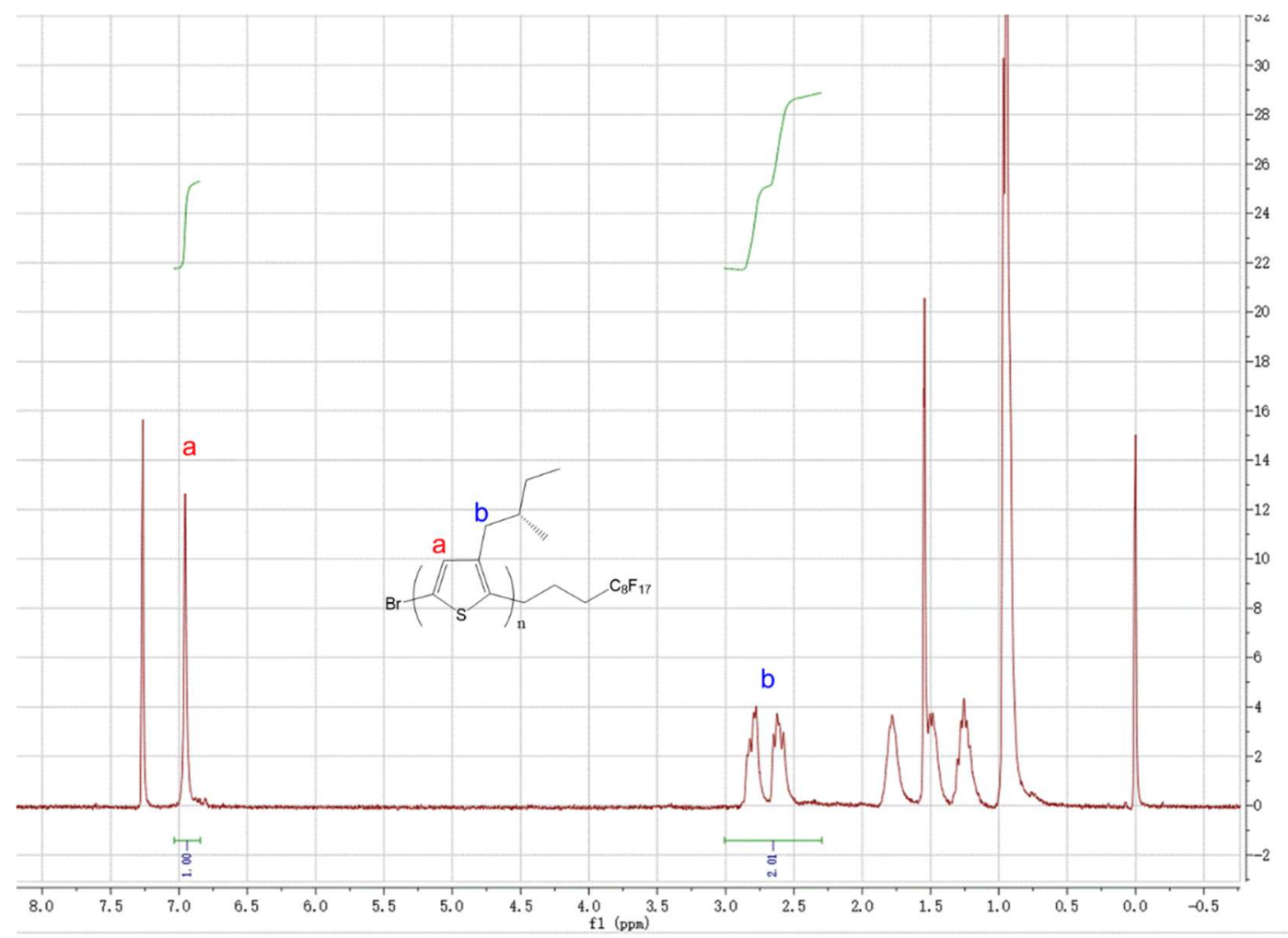

Figure S19. ${ }^{1} \mathrm{H}$ NMR spectrum of $(S)-\mathrm{P} 3 \mathrm{MBT}-\mathrm{F}_{17}$.

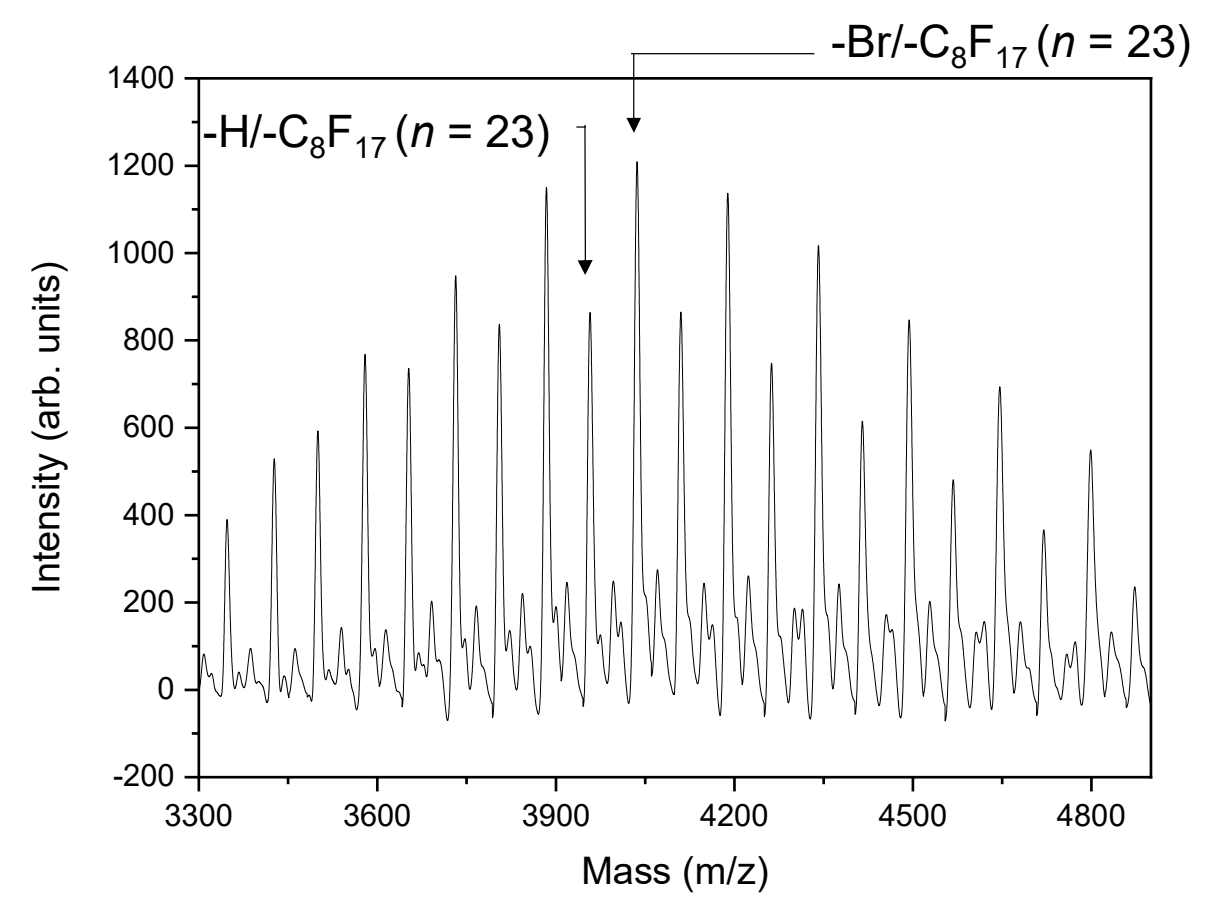

Figure S20. MALDI-TOF-MS spectrum of (S)-P3MBT-F 17. 
(a) F 1s

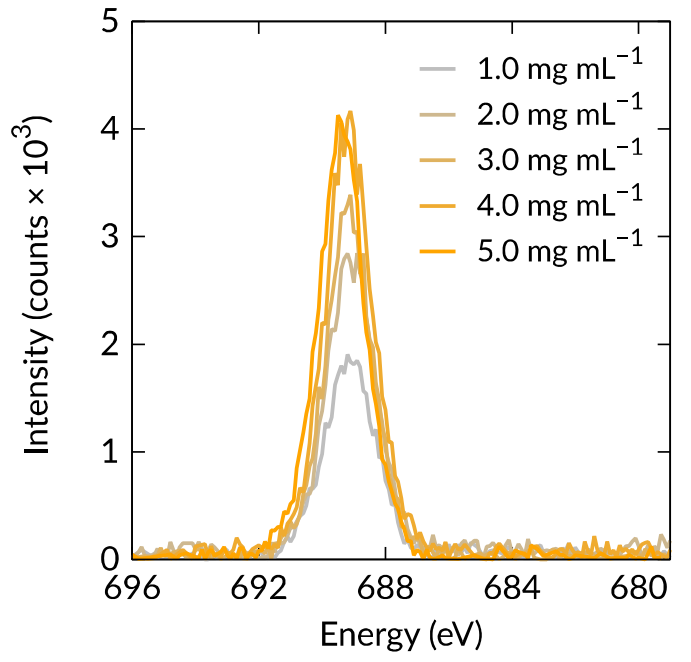

(b) C $1 \mathrm{~s}$

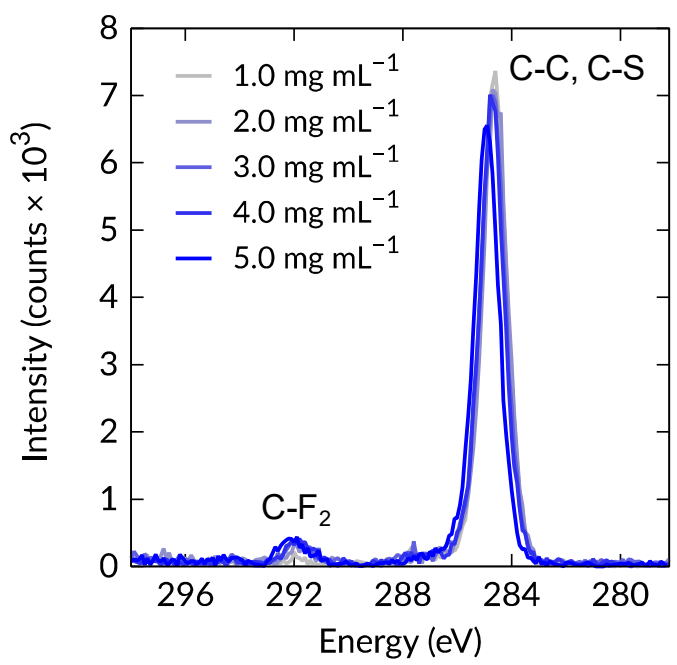

Figure S21. XPS spectra of $(S)-\mathrm{P} 3 \mathrm{MBT}:(S)-\mathrm{P} 3 \mathrm{MBT}-\mathrm{F}_{17}$ thin films in the regions of (a) $\mathrm{F} 1 \mathrm{~s}$ and (b) $\mathrm{C} 1 \mathrm{~s}$ with different $(S)-\mathrm{P} 3 \mathrm{MBT}-\mathrm{F}_{17}$ concentrations in the solution for spincoating. The $\mathrm{F} / \mathrm{C}$ atomic ratios of the surface were calculated from the $\mathrm{F} 1 \mathrm{~s}$ and $\mathrm{C} 1 \mathrm{~s}$ (C-C, C-S) peak areas.

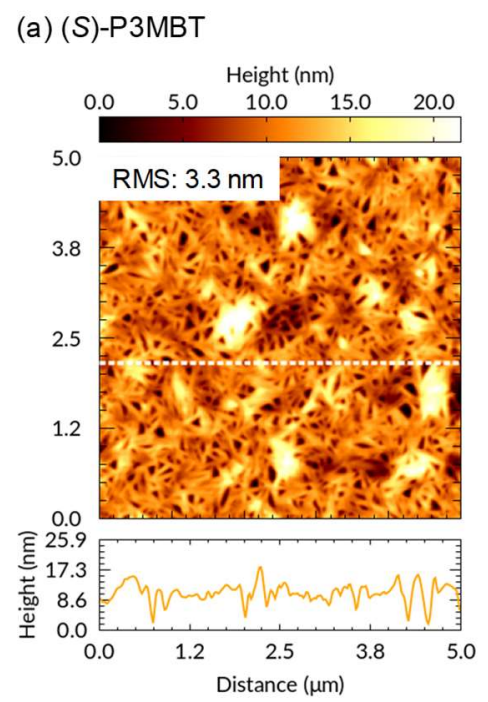

(b) (S)-P3MBT-F 17

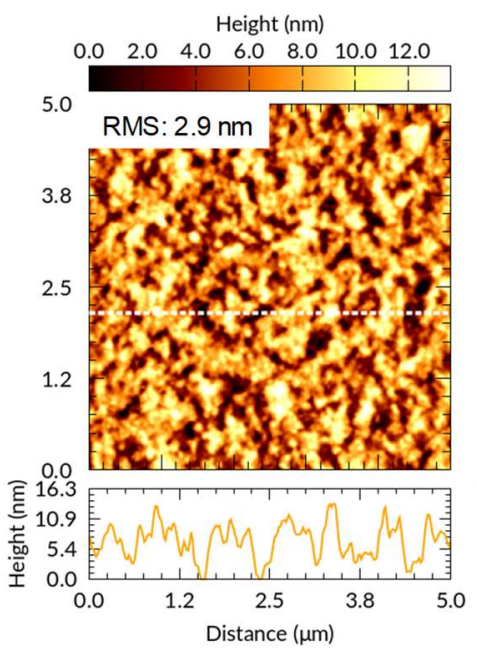

(c) (S)-P3MBT: (S)-P3MBT-F 17

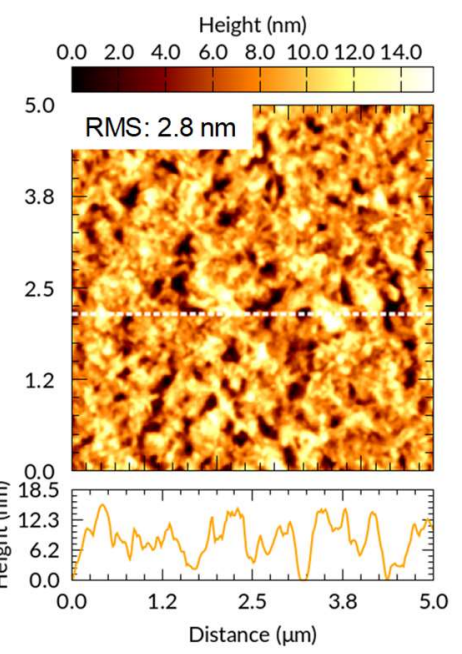

Figure S22. AFM topographic images of (a) $(S)-\mathrm{P} 3 \mathrm{MBT}$, (b) $(S)-\mathrm{P} 3 \mathrm{MBT}-\mathrm{F}_{17}$, and (c) $(S)-\mathrm{P} 3 \mathrm{MBT}$ : $(S)-\mathrm{P} 3 \mathrm{MBT}-\mathrm{F}_{17}$ thin films prepared on Si substrate. Image size: $5 \times 5 \mu \mathrm{m}$. Bottom panels show line profiles at the positions indicated by dashed lines in the images. 

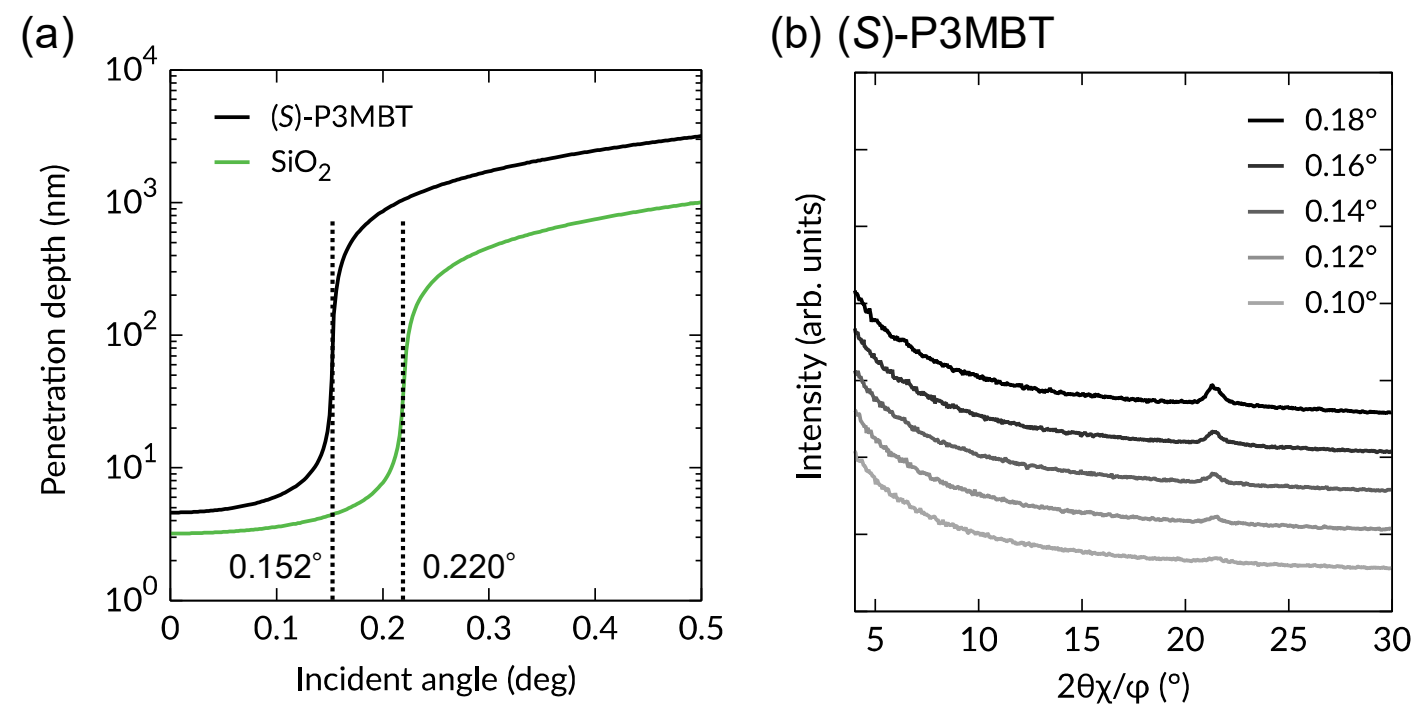

\section{(c) (S)-P3MBT-F 17}

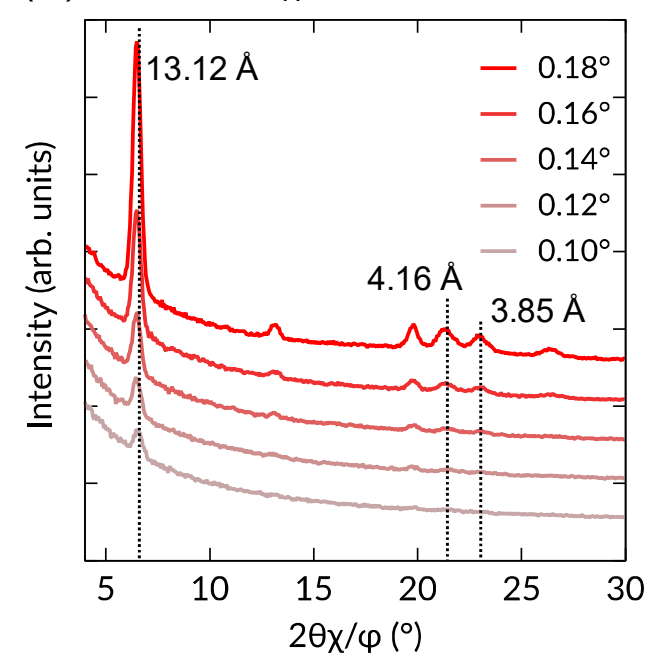

(d) (S)-P3MBT: (S)-P3MBT-F 17

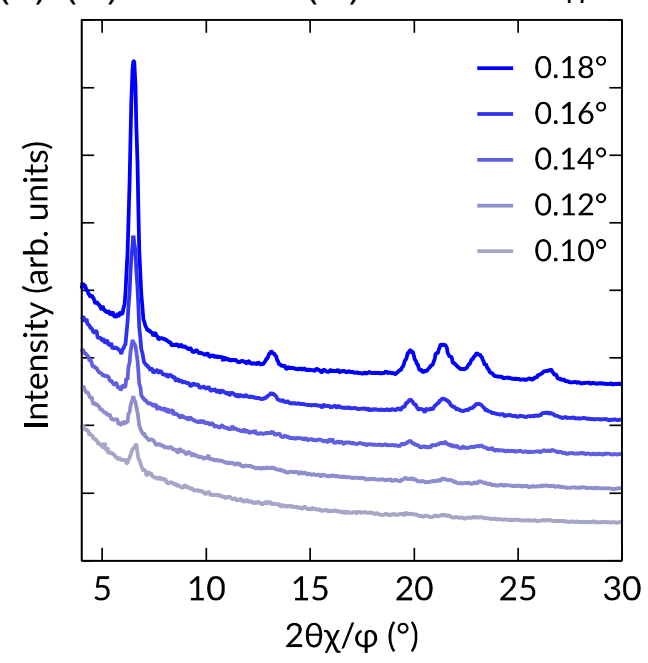

Figure S23. (a) Calculated X-ray penetration depth of (S)-P3MBT and $\mathrm{SiO}_{2}$ film with different incident angle. (b), (c), (d) In-plane XRD patterns of (a) $(S)$-P3MBT, (b) $(S)$ P3MBT-F 17 , and (c) $(S)-\mathrm{P} 3 \mathrm{MBT}$ : $(S)-\mathrm{P} 3 \mathrm{MBT}-\mathrm{F}_{17}$ thin films prepared on Si substrate. The incident angle of $\mathrm{X}$-ray was changed from 0.10 to $0.18^{\circ}$. 